\title{
MAGED2: A novel p53-dissociator
}

\author{
CHRIS PAPAGEORGIO ${ }^{1}$, RAINER BRACHMANN ${ }^{2}$, JUE ZENG ${ }^{2}$, \\ ROBERT CULVERHOUSE ${ }^{3}$, WANGHAI ZHANG ${ }^{4}$ and HOWARD McLEOD ${ }^{5}$
}

\author{
${ }^{1} 115$ Business Loop 70 West, DC 1116.71, Hematology and Medical Oncology, Ellis Fischel Cancer Center, \\ University of Missouri-Columbia, Columbia, MO 65203; ${ }^{2}$ Department of Medicine, Division of Hematology/Oncology, \\ University of California, Irvine, CA 92697; ${ }^{3}$ Division of General Medical Sciences, Washington University School of \\ Medicine, Campus Box 8005, 660 South Euclid Avenue, Saint Louis, MO 63110; ${ }^{4}$ University of North Carolina, \\ Chapel Hill; ${ }^{5}$ School of Pharmacy, University of North Carolina, Chapel Hill, NC 27599, USA
}

Received March 2, 2007; Accepted April 19, 2007

\begin{abstract}
The tumor suppressor protein p53 is a transcription factor that is frequently mutated in human cancers. In response to DNA damage, unmutated or wild-type (wt) p53 protein is stabilized and activated by post-transcriptional modifications that enable it to induce either apoptosis or cell cycle arrest. Using a yeast p53-dissociator assay, we identified MAGED2 as a potential negative regulator of wt p53 activity. Subsequently, using co-immunoprecipitation and reporter gene assays in human cultured cells that are often adopted for functional analysis of p53 we demonstrated that MAGED2 interacted physically with p53 and modified its activity. Finally, we were able to illustrate expression of both p53 and MAGED2 within the same subcellular compartment, i.e. either nucleus or cytoplasm, in 2,682 human cancer tissue specimens using a common cancer tissue microarray and antibodies against MAGED2 and p53. The present results implicate MAGED2, a novel protein, as a p53-dissociator.
\end{abstract}

\section{Introduction}

The tumor suppressor protein p53 is the single most important protein to protect humans from cancer by inducing cell cycle arrest or apoptosis after it has been activated by upstream stress signals (1-5). Approximately $50 \%$ of all human cancers carry p53 gene mutations (6); another 10-20\% show inactivation of the wt p53 protein either by high-risk human papilloma virus E6, as in cervical cancers (7-10), or by overexpression of MDM2, a physiological negative regulator of $\mathrm{p} 53$, as in

Correspondence to: Dr Chris Papageorgio, 1115 Business Loop 70 West, DC 1116.71, Hematology and Medical Oncology, Ellis Fischel Cancer Center, University of Missouri-Columbia, Columbia, MO 65203, USA

E-mail: papageorgioc@health.missouri.edu

Key words: apoptosis, MAGED2, p53-dissociator, Necdin, DNA damage, cell cycle arrest sarcomas (11-15). The p53 status of the remaining 30-40\% of human cancers is currently poorly understood. A significant subset of human tumors, such as neuroblastoma, melanoma and breast cancer appear to have comparatively low rates of p53 mutations and, thus, presumably, inactivate wt p53 via interactions with cellular negative regulators of $\mathrm{p} 53$, known as p53-dissociators $(16,17)$. Indeed, neuroblastoma cells that have wt p53 exhibit an impaired cell cycle arrest in response to various genotoxic stimuli (18-20).

Using a well-validated p53-dissociator assay in yeast $(21,22)$, we screened a cDNA expression library derived from a neuroblastoma (NB) cell line. The reason we opted to work with that particular cell line was that NBs stand out by a conspicuous absence of p53 mutations not only in primary tumors but also in tumor-derived cell lines (23-25) and thus protein-protein interactions or other unknown mechanisms may disrupt wt p53 in such tumor cells. The protein that scored the highest in our yeast p53-dissociator assay was Necdin (NDN) a known p53-dissociator that has been shown to have physical and functional interactions with p53 (26). We then performed a search of protein databanks for NDN-related protein sequences using the blastp program on the Internet server of the National Center for Biotechnology Information (NCBI). We found that NDN showed greatest amino acid homology to the breast cancer associated gene-1 (BCG-1) or more recently termed melanoma antigen, family $\mathrm{D}, 2$ (MAGED2; NCBI accession \# NM 014599). It is speculated, based on the patterns of MAGE expression and observed functions of NDN, that this gene family is involved in cell cycle regulation (27). We therefore decided to investigate the role of MAGED2 in human cells because its function was unknown and via its homology with NDN could be another novel p53-dissociator.

This report suggests that MAGED2 may be a novel p53dissociator not only in human cancer cells but also in human cancer tissues and as such may have implications in cancer management and prognosis.

\section{Materials and methods}

Chemicals and reagents. Enhanced chemiluminescence Western blotting detection reagents were obtained from 
Amersham Pharmacia Biotech (Piscataway, NJ). The secondary antibody was peroxidase-conjugated donkey antirabbit IgG (Santa Cruz Biotechnology, Inc., Santa Cruz, CA). Reagents for immunohistochemistry (Dewax, peroxide block, power block, link, horseradish peroxidase, 3,3-diaminobenzidine tetrahydrochloride, hematoxylin, and buffers) were purchased from BioGenex (San Ramon, CA).

Antibodies. Two polyclonal antibodies for MAGED2 were generated by Genemed Synthesis Inc. (South San Fransisco, CA) and Zymed Laboratories Inc. (South San Fransisco, CA) respectively. Macvector software (Accelrys Inc., San Diego, CA) was used to select an $\mathrm{NH}_{2}$-terminal peptide MAGED2 for generation of antipeptide antibodies. The sequence of the peptide was $\mathrm{H}_{2} \mathrm{~N}-\mathrm{AQSQENQDTRPK-COOH}$. Gameson-Wofs software (DNASTAR, Inc., Madison, WI) was used to select a $\mathrm{COOH}$-terminal peptide for MAGED2 for generation of antipeptide antibodies. The sequence of the peptide was $\mathrm{H}_{2} \mathrm{~N}$ KDPKEWAAQYREAME-COOH. In parallel, two polyclonal antibodies for NDN were generated by Genemed Synthesis Inc. (South San Fransisco, CA). Gameson-Wofs software (Accelrys Inc., San Diego, CA) was used to select both an $\mathrm{NH}_{2}$-terminal and a $\mathrm{COOH}$-terminal peptide of NDN for generation of antipeptide antibodies. For the $\mathrm{NH}_{2}$-terminal of NDN, the sequence of the peptide was $\mathrm{H}_{2} \mathrm{~N}-\mathrm{SEQSKDLSDPNFAAEC}$ $\mathrm{COOH}$ and for the $\mathrm{COOH}$-terminal of NDN the sequence of the peptide was $\mathrm{H}_{2} \mathrm{~N}-\mathrm{KKDPQAWPSRYREALC-COOH}$. Peptides were synthesized, conjugated with keyhole limpet hemocyanin and then injected into rabbits for antibody production. Antibodies against human p53 and p21 were purchased from Dako Corporation (Carpinteria, CA).

SDS-PAGE and Western analysis. The mixtures were heated at $100^{\circ} \mathrm{C}$ for $3 \mathrm{~min}$. Heated mixtures were then centrifuged at $10,000 \mathrm{x} \mathrm{g}$ for $5 \mathrm{~min}$ to remove insoluble materials, and supernatants were subjected to SDS-PAGE (10\%). The proteins were transferred to nitrocellulose membrane in transfer buffer (96 mM glycine, $12 \mathrm{mM}$ Tris base, and 15\% methanol) using a Semiphor Transphor Unit (Amersham Pharmacia Biotech, San Francisco, CA) for $1 \mathrm{~h}$. Immunoblot stains were performed using the rabbit anti-NDN, anti-MAGED2 and standard goat anti-rabbit immunoglobulin as primary and secondary antibodies, respectively. Detection was performed using enhanced chemiluminescence reagents from Amersham Pharmacia Biotech.

Immunohistochemistry. Immunohistochemistry was performed using the streptavidin-biotin complex method, manually, as described previously. For negative controls, slides were incubated in the absence of the respective primary antibody for MAGED2, p53 and p21 (phosphate-buffered saline or PBS only). Slides were scanned with Nikon Eclips (E800) using the MetaMorph imaging system and stored on a disk.

Common cancer tissue array set. The distribution of MAGED2, NDN, p53 and p21 in human tumors was evaluated using tissue arrays of common human cancers and normal tissues purchased from the National Cancer Institute (Bethesda, MD). Each tissue array slide contained 501 samples, each of which was $2 \mathrm{~mm}$ in diameter and $4 \mu \mathrm{m}$ thick. Tissue array slides were mounted on siliconized glass slides and purchased ready for use in immunohistochemistry as fourth generation (TARP4) tissue microarrays. Slides containing no parenchymal cells were not used for evaluation. Final analysis yielded 2,682 evaluable cases of tumor tissues, originating from 3,006 human cancer tissue specimens representing 8 common human cancer types including breast, colon, lung and lymphoma.

Semiquantitative assessment of MAGED2 and NDN. The expression of MAGED2, NDN, p53 and p21 in situ was evaluated by a semiquantitative scoring system. The intensity of staining was scored as 0 (negative), 1 (weak), 2 (medium), or 3 (strong). The extent of staining was scored as $0(0 \%), 1$ (1-25\%), 2 (26-50\%), $3(51-75 \%)$, or 4 (76-100\%), according to the percentage of cells staining positive respectively for MAGED2, NDN, p53 and p21. The sum of the intensity and extent scores was used as the final staining score (0-7) for MAGED2, NDN, p53 and p21 respectively. Tissues with a final staining score of $>2$ were considered to be positive. A final staining score of 2-3 was considered + , a final staining score of 4-5 was considered ++ , and a final staining score of 6-7 was considered +++ .

cDNA libraries, plasmids and plasmid construction. The screened cDNA expression libraries were derived from the SKNSH NB cell line (LOT\#81125; conc. $2.61 \mu \mathrm{g} / \mu 1$; total volume received $1.5 \mathrm{ml}$ ). For the construction of the cDNA library, cDNAs were constructed using oligo(dT) NotI primers and 5' SalI-MluI adaptors as described in the Superscript plasmid system and ligated on SalI-NotI-digested p2.5 vector (22). The following plasmids were used: pFLAG-CMV2 (Sigma), PG13-Luc (S.J. Baker), pRenilla (Promega), pFLAGSV40TAg (T. Wang and R.K. Brachmann), and pCMV-p53 (Clontech Laboratories). For experiments in mammalian cells MAGED2 was cloned into pFLAG-CMV2 and subsequently sequence-confirmed.

Studies in S.cerevisiae. Techniques for yeast maintenance and p53-dissociator assay have been described (22). RBy333 resulted from the mating of two haploid strains, each containing the $p 53$ expression cassette integrated at the LYS2 locus and the $U R A 3$ reporter construct. Also, RBy333 contains the episome pES9 which is responsible for the expression of E6-AP under the control of the inducible promoter MET25 on a $L E U 2$ backbone.

Cell culture, transfection and reporter gene assays. A549 and H1299 cell lines were grown in high-glucose Dulbecco's modified Eagle's medium with $10 \%$ fetal bovine serum. Lipofectamine was used for all transfections. Reporter gene assays were performed as previously described (21).

Co-immunoprecipitation (Co-IP) and immunoblotting (IB). Cells were seeded at $1 \times 10^{6} \mathrm{~mm}$ plate and transfected with $3 \mu \mathrm{g}$ of total DNA. After $24 \mathrm{~h}$, cells were washed with PBS, treated with $1 \mathrm{mM}$ dimethyl 13,3'-dithiobispropionimidate $(2 \mathrm{HCl})$ (DTBP) for $20 \mathrm{~min}$ at room temperature and lysed with $500 \mu \mathrm{l}$ of ELB (50 mM HEPES, pH 7.2; $250 \mathrm{mM} \mathrm{NaCl} ; 5$ mM EDTA, $\mathrm{pH} 8.0 ; 0.5 \%$ NP-40) containing protease and phosphatase 


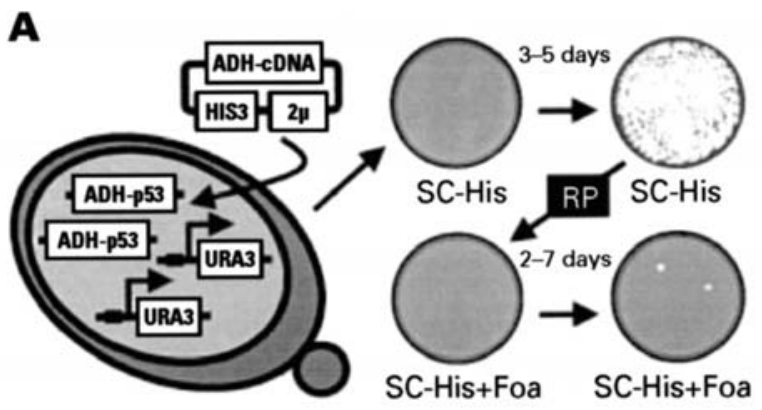

B

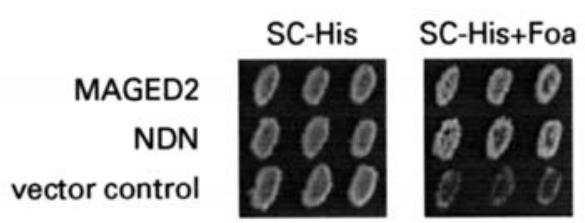

Figure 1. The p53 dissociator assay in S. cerevisiae and p53-dissociators. (A) For our NB library screen, cDNA expression library plasmids were transformed into RBy333, transformants were then placed on plates selecting for the plasmids (SC-His) and replica-plated (RP) after 3-5 days to plates containing FOA (SC-His + 0.1\% FOA). Over the next 2-7 days, $\mathrm{Foa}^{\mathrm{R}}$ clones emerged which were then analyzed further as described previously (48). (B) MAGED2 and NDN isolated as p53-dissociators in a p53-dissociator screen. RBy333 containing NB cDNA library clones for MAGED2 and NDN were replica-plated from SC-His to SC-His $+0.075 \%$ FOA at $30^{\circ} \mathrm{C}$ and growth was evaluated after 3 days. p2.5 was used as vector control.

inhibitors. After gentle rocking for $5 \mathrm{~min}$, samples were pipetted up and down 6-8 times for $10 \mathrm{~min}$, centrifuged twice at $20800 \mathrm{x}$ g for $10 \mathrm{~min}$ and exposed to FLAG-M2 beads (Sigma) for $1-2 \mathrm{~h}\left(0-4^{\circ} \mathrm{C}\right)$. Beads were washed three times with ELB and once with PBS, spun down for 2 min at $500 \mathrm{x} \mathrm{g}$, mixed with 20-30 $\mu 1$ of loading buffer and boiled for 4 min prior to standard immunoblotting analysis. To demonstrate the interaction of p53 and MAGED2, polyclonal anti-p53 antibody conjugated to peroxidase (Boehringer Mannheim) was crosslinked to protein G-agarose (Santa Cruz Biotechnology) with dimethyl pimelimidate (2HCl) (DMP). Normal sheep antimouse IgG-HRP (Amersham Life Sciences) cross-linked to protein G-agarose was the negative control. Immunoblot staining before Co-IP for detection of expression of FLAGtagged MAGED2 and p53 was performed using respectively a mouse monoclonal anti-FLAG M5 antibody (Sigma-Aldrich) and polyclonal anti-p53 antibody conjugated to peroxidase (Boehringer Mannheim).

Statistical analysis. The correlation amongst nuclear readings of proteins MAGED2, NDN, p53 and p21 as well as cytoplasmic readings of the above-mentioned proteins was assessed using weighted $\kappa$ statistics. All comparisons were considered significant at $\mathrm{P}<0.05$.

\section{Results}

Loss of wt p53 is probably the most common molecular abnormality in human neoplasms. Inactivation by mutation is not the sole mechanism of functional p53 disruption, but interactions with cellular proteins acting as p53-dissociators may also affect p53 function. NB cells have wt p53 and an impaired response to DNA damage. We, therefore, performed a p53-dissociator screen of an NB cDNA expression library using a yeast $\mathrm{p} 53$-dissociator assay. A total of $7.02 \times 10^{6}$ transformants yielded $112 \mathrm{Foa}^{\mathrm{R}}$ clones that were confirmed after single-colony purification. Of the $112 \mathrm{Foa}^{\mathrm{R}}$ clones, 94 showed plasmid dependency of the $\mathrm{Foa}^{\mathrm{R}}$ phenotype and 48 were $\mathrm{Foa}^{\mathrm{R}}$ upon retransformation of Rby333 after plasmid rescue. They represented five candidate proteins not previously connected to 553 , as well as NDN, a known p53-modifier, and 53BP1, a known p53-coactivator. NDN scored the highest in our screen (18 of 48 library plasmids in total, 10 independent clones; Fig. 1) and showed the greatest amino-acid homology with MAGED2. Since MAGED2, like NDN, was ubiquitous, we decided to focus on MAGED2 whose function was unknown and could possibly involve p53 interaction in neoplasms with high rates of wt p53 such as breast, melanoma, and lymphoma.

We then obtained an expressed sequence tag (EST) clone for full-length MAGED2 (accession no. NM 014599) and constructed a mammalian expression plasmid, sequenceverified for FLAG-tagged full-length MAGED2. To determine whether MAGED2 influences p53 activity in human cancer cells we transiently transfected p53-positive A549 cells with increasing amounts of FLAG-MAGED2. The results consistently showed respectively no and $30-40 \%$ reduction of p53 transcriptional activity in A549 cells transfected with 250 and 500 ng FLAG-MAGED2 (Fig. 2a). We also transiently transfected p53-negative H1299 cells with p53 and increasing amounts of FLAG-MAGED2. The results were interestingly consistent with a $30-40 \%$ and $10 \%$ reduction of p53 transcriptional activity in H1299 cells transfected with $500 \mathrm{ng}$ and $1 \mu \mathrm{g}$ FLAG-MAGED2 respectively (Fig. 2b). The protein levels of p53 were unaffected by co-expression of FLAGMAGED2. The observed lesser degree of reduction of p53 transcriptional activity induced by the highest concentration of FLAG-MAGED2 in H1299 cells may be cell-type specific or indicate that the interaction between p53 and MAGED2 is transient and highly regulated by other factors. Our Co-IP studies established that FLAG-MAGED2 interacted with exogenous wt p53 and three different types of mutated p53 at its DNA-binding site (DBS) suggesting that the DBS of p53 does not affect the interaction with MAGED2 (Fig. 2c).

Encouraged by the promising data in human cancer cells, we next proceeded to evaluate the expression profile of MAGED2 and NDN in human cancer tissue specimens. Utilizing tissue microarray technology, we examined by immunohistochemistry a total of 3,150 tumor specimens from 8 different tumor types and 357 normal tissue specimens from 29 different normal tissue types, 8 of which corresponded to the 8 types of tumors, for the expression of MAGED2, NDN, p53 and p21 (Table I). The $p 21$ gene is a direct p53 response gene the expression of which, along with the expression of $p 53$, as measured by immunohistochemical staining has traditionally been used to try to differentiate mutant p53 tumors (p53-positive, p21-negative) from tumors with activated wt p53, which also have increased expression of p53-regulated genes (p53-positive, $\mathrm{p} 21$ positive). This approach has been used in a plethora of studies to increase the predictive value of p53 immunostaining for detection of the wt or 
A

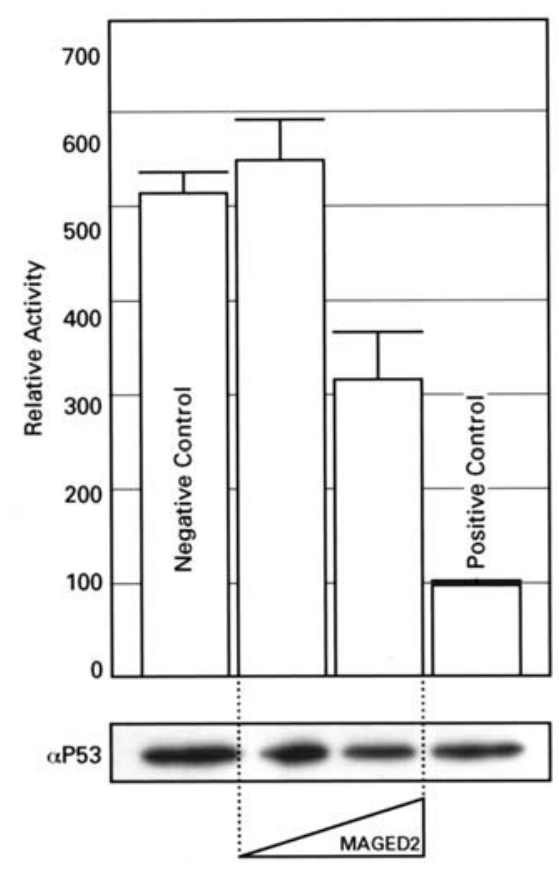

B

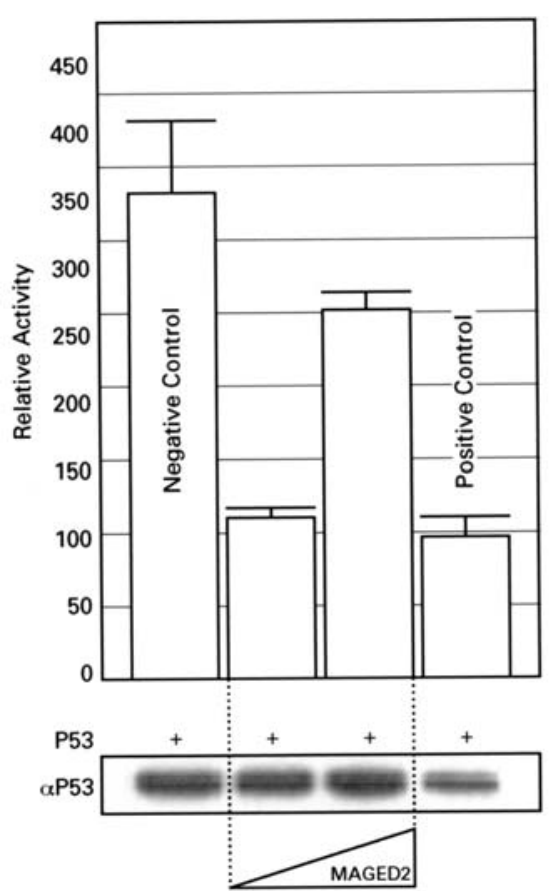

mutational status of p53 as a prognosticator of response to chemotherapy in various human cancers. However, human cancers in tissue microarrays represent unknown clinical specimens consisting of mixed populations of cells with varying cell cycle distributions which may contribute to variations in the cytoplasmic or nuclear distribution of specifically p21/cyclin/CDKs (28-30). For this reason, the question we generated to be statistically tested for acceptance or rejection of the Null Hypothesis examined whether p53 in conjunction with its presumed p53-dissociator, MAGED2, was associated in a statistically significant manner and within the same subcellular compartment with any variation of p21 levels. We raised exactly the same hypothesis for NDN which is already a known p53-dissociator. We used 2 antibodies for NDN and
C

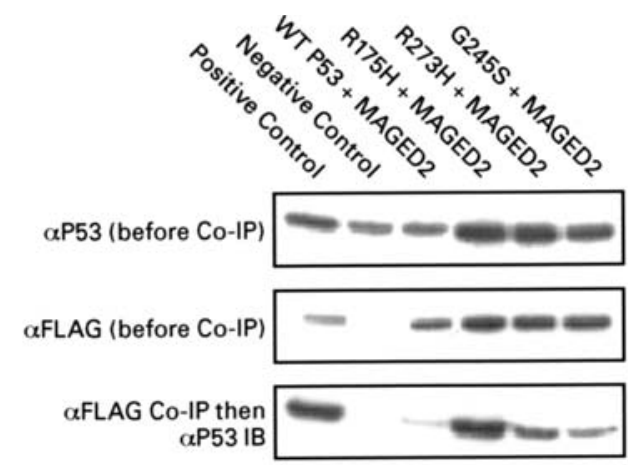

Figure 2. A, analysis of p53 transcriptional activity in p53-positive A549 human cells using p53 reporter gene assays with luciferase. Increasing amounts of an expression plasmid for FLAG-tagged full-length MAGED2 (250 and $500 \mathrm{ng}$ ) were transiently transfected into p53-positive A549 cells. Vector control was used as negative control and SV40 large T antigen, a known p53 protein inhibitor, was used as positive control. Error bars represent standard deviation for three independent experiments. The protein levels of p53 were unaffected by co-expression of FLAG-MAGED2 as evidenced by immunoblotting performed with anti-p53 antibody after the cell lysates of the shown reporter gene assay had been adjusted to control for Renilla luciferase activity. Error bars represent standard deviation for three independent experiments. B, analysis of p53 transcriptional activity in p53-negative H1299 human cells using p53 reporter gene assays with luciferase. Increasing amounts of an expression plasmid for FLAG-tagged full-length MAGED2 (250 and $500 \mathrm{ng}$ ) were transiently co-transfected with the p53 expression plasmid (100 ng) into p53-negative H1299 cells. Vector control was used as negative control and SV40 large T antigen, a known p53 protein inhibitor, was used as positive control. Error bars represent standard deviation for three independent experiments. The protein levels of p53 were unaffected by co-expression of FLAG-MAGED2 as evidenced by immunoblotting performed with anti-p53 antibody after the cell lysates of the shown reporter gene assay had been adjusted to control for Renilla luciferase activity. C, co-immunoprecipitation (IP) and immunoblotting (IB) assays. To demonstrate the interaction of p53 and MAGED2, FLAG-tagged MAGED2 $(2 \mu \mathrm{g})$ was co-transfected transiently with wt p53 $(1 \mu \mathrm{g})$ and three different p53 mutants: R175H $(1 \mu \mathrm{g}), \mathrm{R} 273 \mathrm{H}$ $(1 \mu \mathrm{g})$ and $\mathrm{G} 245 \mathrm{~S}(1 \mu \mathrm{g})$. Immunoblot staining before IP for FLAG-tagged MAGED2 was detected using a monoclonal anti-FLAG M5 antibody (SigmaAldrich); p53 was detected using anti-p53 polyclonal antibody BMG-1B1 (Boehringer Mannheim) conjugated to peroxidase raised against wt and mutant p53. Immunoblot staining after IP was performed with anti-p53 polyclonal antibody BMG-1B1 (Boehringer Mannheim) conjugated to peroxidase raised against wt and mutant p53. It was evident that FLAG-MAGED2 interacted with exogenous wt pt and three different types of cancer mutants suggesting that the DNA-binding domain of p53 does not affect the interaction with MAGED2. Vector control was used as negative control and SV40 large T-cell antigen was used as a positive control.

MAGED2 respectively, raised against the $\mathrm{N}^{\prime}$ and $\mathrm{C}^{\prime}$ terminus of each protein and determined their specificity by Western blotting in $\mathrm{H} 1299$ cells. A $\kappa$-weighted statistics model showed that tumor tissues with high levels of expression of nuclear p53 and accompanying high levels of nuclear MAGED2 had statistically significant variation, i.e. either very low or very high nuclear p21 levels. We also demonstrated that tumor tissues with high levels of expression of cytoplasmic p53 and accompanying high levels of cytoplasmic MAGED2 had statistically significant variation, i.e. either very low or very high cytoplasmic p21 levels (Fig. 3). Each one of the 2 antibodies against MAGED2 and each one of the 2 antibodies against NDN produced similar statistically significant results; interestingly, the antibody against the $\mathrm{C}^{\prime}$ terminus of MAGED2 
Table I. Protein staining in nucleus and cytoplasm subdivided by sample tissue type.

\begin{tabular}{|c|c|c|c|c|c|c|c|c|c|c|c|c|c|c|c|c|c|c|c|}
\hline \multirow[b]{2}{*}{ Tissue type } & & \multicolumn{3}{|c|}{$\begin{array}{c}\text { Necdin ab } \\
\text { against the } \\
\mathrm{NH}^{2} \text {-terminal }\end{array}$} & \multicolumn{3}{|c|}{$\begin{array}{c}\text { Necdin ab } \\
\text { against the } \\
\text { COOH-terminal }\end{array}$} & \multicolumn{3}{|c|}{$\begin{array}{l}\text { MAGED2 ab } \\
\text { against the } \\
\mathrm{NH}^{2} \text {-terminal }\end{array}$} & \multicolumn{3}{|c|}{$\begin{array}{l}\text { MAGED2 ab } \\
\text { against the } \\
\text { COOH-terminal }\end{array}$} & \multicolumn{3}{|c|}{ p53 } & \multicolumn{3}{|c|}{ p21 } \\
\hline & & $\mathrm{L}$ & $\mathrm{H}$ & M & $\mathrm{L}$ & $\mathrm{H}$ & M & $\mathrm{L}$ & $\mathrm{H}$ & M & $\mathrm{L}$ & $\mathrm{H}$ & M & $\mathrm{L}$ & $\mathrm{H}$ & $\mathrm{M}$ & $\mathrm{L}$ & $\mathrm{H}$ & M \\
\hline \multirow[t]{2}{*}{ Brain cancer } & $\mathrm{N}$ & 18 & 1 & 6 & 6 & 13 & 6 & 11 & 9 & 5 & 13 & 9 & 3 & 15 & 6 & 4 & 21 & 0 & 4 \\
\hline & $\mathrm{C}$ & 18 & 1 & & 9 & 10 & & 12 & 8 & & 2 & 20 & & 21 & 0 & & 21 & 0 & \\
\hline \multirow[t]{2}{*}{ Breast cancer } & $\mathrm{N}$ & 38 & 9 & 28 & 12 & 39 & 24 & 35 & 17 & 23 & 23 & 32 & 20 & 36 & 16 & 23 & 62 & 1 & 12 \\
\hline & $\mathrm{C}$ & 45 & 2 & & 27 & 24 & & 19 & 33 & & 8 & 47 & & 51 & 1 & & 63 & 0 & \\
\hline \multirow[t]{2}{*}{ Colon cancer } & $\mathrm{N}$ & 58 & 0 & 17 & 17 & 39 & 19 & 30 & 19 & 26 & 36 & 21 & 18 & 40 & 20 & 15 & 63 & 0 & 12 \\
\hline & $\mathrm{C}$ & 52 & 6 & & 18 & 38 & & 18 & 31 & & 13 & 44 & & 59 & 1 & & 62 & 1 & \\
\hline \multirow[t]{2}{*}{ Lung cancer } & $\mathrm{N}$ & 53 & 0 & & 24 & 28 & 23 & 33 & 15 & 27 & 41 & 17 & 17 & 40 & 13 & 22 & 55 & 1 & 19 \\
\hline & $\mathrm{C}$ & 53 & 0 & & 22 & 30 & & 30 & 18 & & 4 & 54 & & 53 & 0 & & 56 & 0 & \\
\hline \multirow[t]{2}{*}{ Lymphoma } & $\mathrm{N}$ & 46 & 1 & 3 & 12 & 35 & 3 & 27 & 16 & 7 & 27 & 20 & 3 & 43 & 5 & 2 & 47 & 0 & 3 \\
\hline & $\mathrm{C}$ & 47 & 0 & & 24 & 23 & & 30 & 13 & & 13 & 34 & & 48 & 0 & & 47 & 0 & \\
\hline \multirow[t]{2}{*}{ Melanoma } & $\mathrm{N}$ & 18 & 0 & 7 & 1 & 13 & 11 & 13 & 5 & 7 & 11 & 9 & 5 & 15 & 6 & 4 & 20 & 0 & 5 \\
\hline & $\mathrm{C}$ & 16 & 2 & & 1 & 13 & & 9 & 9 & & 1 & 19 & & 19 & 2 & & 20 & 0 & \\
\hline \multirow[t]{2}{*}{ Normal } & $\mathrm{N}$ & 35 & 0 & 16 & 22 & 11 & 18 & 30 & 2 & 19 & 32 & 2 & 17 & 37 & 0 & 14 & 46 & 0 & 5 \\
\hline & $\mathrm{C}$ & 33 & 2 & & 11 & 22 & & 20 & 12 & & 1 & 33 & & 35 & 2 & & 45 & 1 & \\
\hline \multirow[t]{2}{*}{ Ovarian cancer } & $\mathrm{N}$ & 43 & 0 & 7 & 16 & 20 & 14 & 21 & 10 & 19 & 20 & 21 & 9 & 26 & 19 & 5 & 43 & 0 & 7 \\
\hline & $\mathrm{C}$ & 41 & 2 & & 7 & 29 & & 23 & 8 & & 2 & 39 & & 45 & 0 & & 43 & 0 & \\
\hline \multirow[t]{2}{*}{ Prostate cancer } & $\mathrm{N}$ & 63 & 0 & 12 & 0 & 62 & 13 & 40 & 17 & 18 & 13 & 49 & 13 & 60 & 2 & 13 & 65 & 0 & 10 \\
\hline & $\mathrm{C}$ & 63 & 0 & & 2 & 60 & & 37 & 20 & & 1 & 61 & & 61 & 1 & & 64 & 1 & \\
\hline \multirow[t]{2}{*}{ Summary } & $\mathrm{N}$ & 372 & 11 & 118 & 110 & 260 & 131 & 240 & 110 & 151 & 216 & 180 & 105 & 312 & 87 & 102 & 422 & 2 & 77 \\
\hline & $\mathrm{C}$ & 368 & 15 & & 121 & 249 & & 198 & 152 & & 45 & 351 & & 392 & 7 & & 421 & 3 & \\
\hline
\end{tabular}

Sample sizes: brain, 25; breast, 75; colon, 75; lung, 75; lymphoma, 50; melanoma, 25; normal, 51; ovarian, 50; prostate, 75 (total, 501). L, low staining; $\mathrm{H}$, high staining; $\mathrm{M}$, missing; $\mathrm{N}$, nuclear staining; $\mathrm{C}$, cytoplasm staining; ab, antibody.

generated highly statistically significant results. The correlation of data between both antibodies against MAGED2 was significant.

\section{Discussion}

The present study demonstrates that MAGED2 can, like its homologue, NDN, be placed into a group of p53-interacting proteins. Both MAGED2 and NDN belong to the MAGE superfamily (31) the precise cellular role of which remains unclear. The clearest evidence of a physiological role for the $M A G E$ genes has come from NDN which appears to be playing a role in the development or maintenance of hypothalamic neurons by enhancing p53-induced cell cycle arrest yet, intriguingly, inhibiting p53-mediated apoptosis $(26,32,33)$. In other words, NDN facilitates cell cycle arrest but promotes cell survival of nerve cells. Our observed lesser degree of reduction of p53 transcriptional activity induced by the highest concentration of FLAG-MAGED2 in H1299 cells may be, as stated above, cell-type specific; it may also suggest that the interaction between p53 and MAGED2 may be labile and

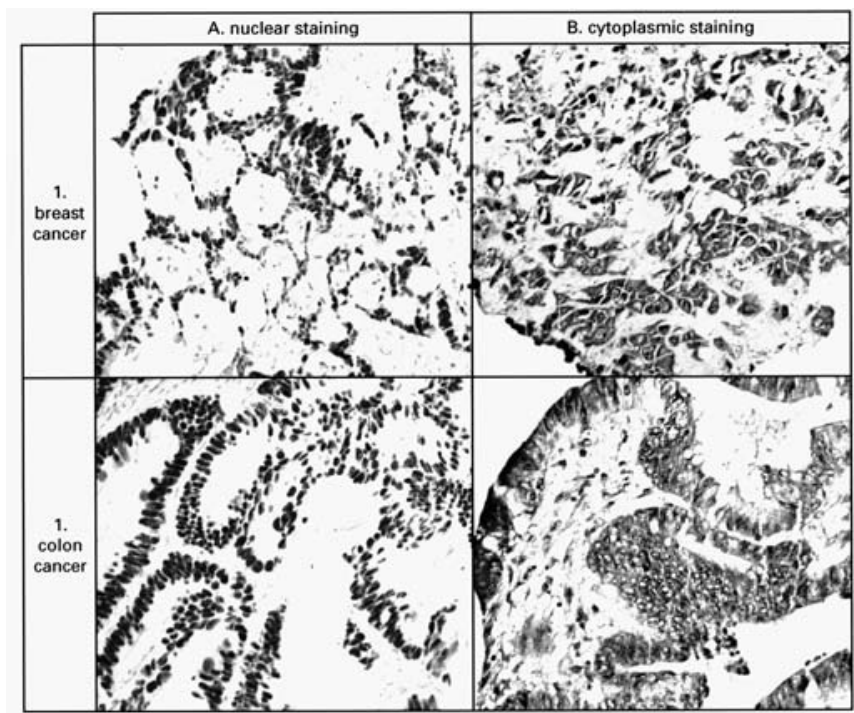

Figure 3. Immunohistochemical detection of p53 and MAGED2 in human cancer tissues. Shown are representative photomicrographs of sections of breast cancer $(1 \mathrm{~A}, 1 \mathrm{~B})$ and colon cancer $(2 \mathrm{~A}, 2 \mathrm{~B})$ depicting nuclear $(1 \mathrm{~A}$, 2A) and cytoplasmic staining (1B, 2B). Original magnification x200. 
may involve other binding factors depending on the cellular microenvironment as it occurs between NDN and p53. Our results are in agreement with the findings by Taniura et al (26) suggesting that, like NDN, MAGED2 binds p53 at a domain other than its DBS. Given the effects of NDN on cell cycle progression and its ability to regulate p53, it will be important to determine whether MAGED2 has similar cellular roles. MAGED2, contrary to the predominantly brain-specific NDN, is expressed in human lung, brain, pancreas, skeletal muscle, heart, placenta, and kidney (34). Although progress on the cellular roles of MAGE proteins is beginning to accelerate, study in this area is nascent. Analysis of the structures of members of the MAGE superfamily does not permit a definite conclusion concerning the mechanism of the selective expression profile of some members of the MAGE superfamily in tumors (31). Indeed, NDN and many of the MAGED family members are broadly expressed during development and several are highly expressed in various forms of cancer (35-40). It is not known yet whether expression of $N D N$ or MAGED genes has any effect on cellular transformation or tumor progression, but studies from diverse areas now suggest important roles for both $N D N$ and MAGED proteins in cell survival, cell cycle progression and apoptosis (40). The high degree of conservation of certain domains among all MAGE members suggests a common general function served by these domains. Defining binding partners such as p53 of family members such as the ubiquitously expressed MAGED2 will no doubt provide insights into the fundamental cellular roles of all family members not only in tumorigenesis but also in neurogenetic disease.

Tissue microarray technology was used to provide a 'total body scan' of our protein of interest. This technology enables researchers not only to have access to valuable human specimens for specific research but also to perform more efficient studies than possible with conventional slides (41). Although the assumption must be made that the $2.0-\mathrm{mm}-$ diameter specimen is representative of the tissue of interest, tissue arrays offer an important step to providing context and data large enough for a statistical analysis like ours. What our human cancer tissue microarray data suggests is that, in a range of human cancer tissues, when MAGED2 co-localizes with p53 in the nucleus or cytoplasm it is linked with a significant modification of p53 activity within that same subcellular compartment. Of course, it is important to realize that IHC studies designed to yield meaningful results are very timeconsuming and moreover, difficult to interpret for the following reasons. Negative IHC for p53 can indicate wt p53 status or deleted $p 53$ genes. Positive IHC for p53 is commonly but not always associated with p53 mutations (16) some of which may act as transdominant negative mutations in p53-heterozygous tumor cells, i.e. as tumorigenic through gain-of-function. The function of p21 in growth arrest after DNA damage in response to activated $\mathrm{p} 53$ has recently been overshadowed by its role in concomitant apoptosis prevention, mitogenesis and tumorigenesis (42). Lastly, MAGED2, like NDN, may enhance p53-mediated growth suppression via a p21-independent pathway in certain cancers where low rather than high levels of p21 can be observed (26). Thus, the statistically significant variation of $\mathrm{p} 21$ levels observed in our tissue microarrays may be due to either a labile interaction between p53 and MAGED2 as indicated by our findings in human cancer cells or the fact that the molecular biology of p21 remains for the most part unknown. Indeed, p21 can have a p53-independent role as it has been described in the development of at least some neoplasms (43). Despite the imperfections described above of interpretation of IHC studies, we would like to state explicitly that if wt p53 protein accumulates to levels detectable by IHC, it is almost inescapable to conclude that this 533 protein does not act as wt protein since high levels of functional p53 protein seem to be incompatible with growth. Thus, we can conclude that protein-protein interactions like the one we are proposing may disrupt wt p53 function in such tumor cells. It is beyond the scope of this article to review the plethora of IHC studies on p53 as a predictor of response to chemotherapy in various human cancers.

In summary, our data suggest that MAGED2, like its homologue NDN, interacts physically with p53 and impairs its transcriptional activity in human cancer cells. This interaction may also be observed in human cancer tissues as statistically significant correlations between p53 and its p53dissociator (NDN or MAGED2) have been made only when p53 and its dissociator are co-localized within the same subcellular compartment across all cancer types tested. The human $M A G E$ genes and proteins constitute an intriguing gene family under increasing attention because of the emerging roles of two of the family's members, MAGED1 and Necdin in cell cycle progression, apoptosis and neurogenetic disease $(36,44)$. As far as we know this is the first study that suggests a physiological cellular role for MAGED2 which is considered the ancestor of all the MAGE genes $(34,45)$. Recently, Harper et al (46) identified a novel MAGED2 antisense RNA transcript in human tissues which may potentially have important implications for future studies examining MAGED2 expression patterns in cancer and normal tissues. Future study in this area should focus on, among other methods, antisense and small molecule inhibitor techniques to transiently inhibit MAGED2 in animal studies and subsequently clinical trials. Restoration of p53 function has already been demonstrated to lead tumor regression in vivo (47). These results support efforts to treat human cancers by way of pharmacological reactivation of p53 which at the present time holds much promise.

\section{Acknowledgments}

This study was supported by a grant from the Association for International Cancer Research (AICR ref\# 01-209). The authors would like to thank Michael C. Perry, MD and Carl E. Freter, $\mathrm{MD} / \mathrm{PhD}$ for their insightful critiques in preparation of the manuscript. Special thanks to Ms. Liz Priddy for her assistance with the figures and table.

\section{References}

1. Ko LJ and Prives C: p53: puzzle and paradigm. Genes Dev 10: 1054-1072, 1996.

2. Koumenis C, Alarcon R, Hammond E, et al: Regulation of p53 by hypoxia: dissociation of transcriptional repression and apoptosis from p53-dependent transactivation. Mol Cell Biol 21: 1297-1310, 2001.

3. Levine AJ: p53, the cellular gatekeeper for growth and division. Cell 88: 323-331, 1997 
4. Giaccia AJ and Kastan MB: The complexity of p53 modulation: emerging patterns from divergent signals. Genes Dev 12: 2973-2983, 1998.

5. Oren M: Tumor suppressor perspective. Exp Cell Res 264: 1, 2001.

6. Pfeifer GP and Holmquist GP: Mutagenesis in the P53 gene. Biochim Biophys Acta 1333: M1-M8, 1997.

7. zur Hausen H: Proliferation-inducing viruses in non-permissive systems as possible causes of human cancers. Lancet 357 : 381-384, 2001.

8. zur Hausen H: Viruses in human cancers. Eur J Cancer 35: $1878-1885,1999$.

9. Scheffner M, Takahashi T, Huibregtse JM, Minna JD and Howley PM: Interaction of the human papillomavirus type 16 E6 oncoprotein with wild-type and mutant human p53 proteins. J Virol 66: 5100-5105, 1992.

10. Traidej M, Chen L, Yu D, Agrawal S and Chen J: The roles of E6-AP and MDM2 in p53 regulation in human papillomaviruspositive cervical cancer cells. Antisense Nucleic Acid Drug Dev 10: 17-27, 2000.

11. Oliner JD, Pietenpol JA, Thiagalingam S, Gyuris J, Kinzler KW and Vogelstein B: Oncoprotein MDM2 conceals the activation domain of tumour suppressor p53. Nature 362: 857-860, 1993.

12. Levav-Cohen Y, Haupt S and Haupt Y: Mdm2 in growth signaling and cancer. Growth Factors 23: 183-192, 2005.

13. Haupt Y, Maya R, Kazaz A and Oren M: Mdm2 promotes the rapid degradation of p53. Nature 387: 296-299, 1997.

14. Oda Y, Sakamoto A, Satio T, Kawauchi S, Iwamoto Y and Tsuneyoshi M: Molecular abnormalities of p53, MDM2, and H-ras in synovial sarcoma. Mod Pathol 13: 994-1004, 2000.

15. Kubbutat MH, Jones SN and Vousden KH: Regulation of p53 stability by Mdm2. Nature 387: 299-303, 1997.

16. Weller M: Predicting response to cancer chemotherapy: the role of p53. Cell Tissue Res 292: 435-445, 1998.

17. Weller M, Bornemann A, Stander M, Schabet M, Dichgans J and Meyermann R: Humoral immune response to p53 in malignant glioma. J Neurol 245: 169-172, 1998.

18. Moll UM, LaQuaglia M, Benard J and Riou G: Wild-type p53 protein undergoes cytoplasmic sequestration in undifferentiated neuroblastomas but not in differentiated tumors. Proc Natl Acad Sci USA 92: 4407-4411, 1995.

19. Moll UM, Ostermeyer AG, Haladay R, Winkfield B, Frazier M and Zambetti G: Cytoplasmic sequestration of wild-type p53 protein impairs the G1 checkpoint after DNA damage. Mol Cell Biol 16: 1126-1137, 1996.

20. Aladjem MI, Spike BT, Rodewald LW, Hope TJ, Klemm M, Jaenisch R and Wahl GM: ES cells do not activate p53-dependent stress responses and undergo p53-independent apoptosis in response to DNA damage. Curr Biol 8: 145-155, 1998.

21. Brachmann RK, Yu K, Eby Y, Pavletich NP and Boeke JD: Genetic selection of intragenic suppressor mutations that reverse the effect of common p53 cancer mutations. EMBO J 17 : 1847-1859, 1998.

22. Vidal M, Brachmann RK, Fattaey A, Harlow E and Boeke JD: Reverse two-hybrid and one-hybrid systems to detect dissociation of protein-protein and DNA-protein interactions. Proc Natl Acad Sci USA 93: 10315-10320, 1996.

23. Vogan K, Bernstein M, Leclerc JM, et al: Absence of p53 gene mutations in primary neuroblastomas. Cancer Res 53: 5269-5273, 1993.

24. Imamura J, Bartram CR, Berthold F, Harms D, Nakamura H and Koeffler HP: Mutation of the p53 gene in neuroblastoma and its relationship with N-myc amplification. Cancer Res 53: 4053-4058, 1993

25. Komuro H, Hayashi Y, Kawamura M, et al: Mutations of the p53 gene are involved in Ewing's sarcomas but not in neuroblastomas. Cancer Res 53: 5284-5288, 1993.

26. Taniura H, Matsumoto $\mathrm{K}$ and Yoshikawa K: Physical and functional interactions of neuronal growth suppressor necdin with p53. J Biol Chem 274: 16242-16248, 1999.

27. Ohman Forslund $\mathrm{K}$ and Nordqvist $\mathrm{K}$ : The melanoma antigen genes - any clues to their functions in normal tissues? Exp Cell Res 265: 185-194, 2001.
28. Winters ZE, Hunt NC, Bradburn MJ, Royds JA, Turley H Harris AL and Norbury CJ: Subcellular localisation of cyclin B Cdc2 and p21(WAF1/CIP1) in breast cancer: association with prognosis. Eur J Cancer 37: 2405-2412, 2001

29. Weiss RH and Randour CJ: The permissive effect of p21(Waf1/ Cip1) on DNA synthesis is dependent on cell type: effect is absent in p53-inactive cells. Cell Signal 12: 413-418, 2000.

30. Weiss RH: p21Waf1/Cip1 as a therapeutic target in breast and other cancers. Cancer Cell 4: 425-429, 2003.

31. Kirkin AF, Dzhandzhugazyan KN and Zeuthen J: Cancer/testis antigens: structural and immunobiological properties. Cancer Invest 20: 222-236, 2002.

32. Taniura H, Taniguchi N, Hara M and Yoshikawa K: Necdin, a postmitotic neuron-specific growth suppressor, interacts with viral transforming proteins and cellular transcription factor E2F1. J Biol Chem 273: 720-728, 1998.

33. Hayashi Y, Matsuyama K, Takagi K, Sugiura H and Yoshikawa K: Arrest of cell growth by necdin, a nuclear protein expressed in postmitotic neurons. Biochem Biophys Res Commun 213: 317-324, 1995

34. Langnaese K, Kloos DU, Wehnert M, Seidel B and Wieacker P Expression pattern and further characterization of human MAGED2 and identification of rodent orthologues. Cytogenet Cell Genet 94: 233-240, 2001.

35. Sasaki M, Nakahira K, Kawano Y, et al: MAGE-E1, a new member of the melanoma-associated antigen gene family and its expression in human glioma. Cancer Res 61: 4809-4814, 2001.

36. Muscatelli F, Abrous DN, Massacrier A, Boccaccio I, Le Moal M, $\mathrm{Cau} \mathrm{P}$ and Cremer H: Disruption of the mouse Necdin gene results in hypothalamic and behavioral alterations reminiscent of the human Prader-Willi syndrome. Hum Mol Genet 9: 3101-3110, 2000 .

37. Niinobe M, Koyama K and Yoshikawa K: Cellular and subcellular localization of necdin in fetal and adult mouse brain. Dev Neurosci 22: 310-319, 2000.

38. Salehi AH, Roux PP, Kubu CJ, et al: NRAGE, a novel MAGE protein, interacts with the p75 neurotrophin receptor and facilitates nerve growth factor-dependent apoptosis. Neuron 27: 279-288, 2000

39. Masuda Y, Sasaki A, Shibuya H, Ueno N, Ikeda K and Watanabe K: Dlxin-1, a novel protein that binds Dlx 5 and regulates its transcriptional function. J Biol Chem 276: 5331-5338, 2001

40. Barker PA and Salehi A: The MAGE proteins: emerging roles in cell cycle progression, apoptosis, and neurogenetic disease. J Neurosci Res 67: 705-712, 2002.

41. Zhang W, Xu G and McLeod HL: Comprehensive evaluation of carboxylesterase-2 expression in normal human tissues using tissue array analysis. Appl Immunohistochem Mol Morphol 10 374-380, 2002

42. Heeren PA, Kloppenberg FW, Hollema H, Mulder NH, Nap RE and Plukker JT: Predictive effect of p53 and p21 alteration on chemotherapy response and survival in locally advanced adenocarcinoma of the esophagus. Anticancer Res 24: 2579-2583, 2004

43. Biankin AV, Kench JG, Morey AL, et al: Overexpression of p21(WAF1/CIP1) is an early event in the development of pancreatic intraepithelial neoplasia. Cancer Res 61: 8830-8837, 2001 .

44. Bertrand M, Huijbers I, Chomez P and De Backer O: Comparative expression analysis of the MAGED genes during embryogenesis and brain development. Dev Dyn 230: 325-334, 2004.

45. Lucas S, Brasseur F and Boon T: A new MAGE gene with ubiquitous expression does not code for known MAGE antigens recognized by T cells. Cancer Res 59: 4100-4103, 1999.

46. Harper R, Xu C, Di P, Chen Y, Privalsky M and Wu R Identification of a novel MAGE D2 antisense RNA transcript in human tissues. Biochem Biophys Res Commun 324: 199-204, 2004

47. Ventura A, Kirsch DG, McLaughlin ME et al: Restoration of p53 function leads to tumour regression in vivo. Nature 445: 661-665, 2007.

48. Wang T, Kobayashi T, Takimoto R, Denes AE, Snyder EL, el-Deiry WS and Brachmann RK: hADA3 is required for p53 activity. EMBO J 20: 6404-6413, 2001 